(Journal of Civil Engineering, Building and Transportation)

\title{
Analisa Struktur Box Girder Jalan Layang Kereta Api Kualanamu
}

\section{Structure Analysis of Girder Box Overpass Kualanamu Railway}

\author{
Muhammad Ridwan*, Irwan \& Subur Panjaitan \\ Program Studi Teknik Sipil, Fakultas Teknik, Universitas Amir Hamzah, Indonesia \\ *Coresponding Email: E-mail : ridwanadry@gmail.com
}

\begin{abstract}
Abstrak
Pembangunan jalan layang kereta api sepanjang $\pm 8 \mathrm{~km}$ yang merupakan bagian dari rencana membangun jalur Stasiun Medan-Stasiun Bandara Kualanamu dengan total panjang $27 \mathrm{~km}$ merupakan bagian dari rencana pembangunan "Indonesia-sentris" yang tidak lagi terkonsentrasi di Pulau Jawa. Penggunaan beton prategang sangat mendukung pembangunan infrastruktur Indonesia, khususnya Jalan Layang Kereta Api Kualanamu di kota Medan yang menggunakan box girder dengan tinggi penampang $2400 \mathrm{~mm}$ sebagai komponen strukturalnya. Studi kasus beton prategang box girder Jalan Layang Kereta Api Kualanamu dengan bentang 40 meter dibagi dalam 15 (lima belas) segmen yang selanjutnya akan dihubungkan antar segmennya dengan proses stressing (pemberian gaya prategang). Studi ini menjelaskan keefektifan penampang girdernya yang memiliki tendon-tendon internal yang diisi kabel baja strand diameter $12,7 \mathrm{~mm}$ berjumlah 60 buah. Selanjutnya, menganalisa persentase kehilangan gaya prategang yang terjadi pada tendonnya akibat perpendekan elastis, gesekan pada tendon, rangkak, susut pada beton dan sebagainya. Semua data yang diperoleh di lapangan, berasal di PT. Wijaya Karya Beton Tbk dan analisa beban dengan metode SNI T-12 2004. Sebagai tambahan diperkenalkan langkah-langkah proses produksi beton prategang box girder, mulai dari penulangan sampai pengecoran di pabrik beton pracetak. Kehilangan gaya prategang yang terjadi sebesar 12,94 \%. Kata kunci : Beton Prategang, Box Girder, Kehilangan Gaya Prategang
\end{abstract}

\begin{abstract}
The $\pm 8 \mathrm{~km}$ railway overpass construction which is part of the plan to build the Medan-Kualanamu Airport Station with a total length of $27 \mathrm{~km}$ is part of Indonesia-centric development plan which is no longer concentrated in Java. The use of prestressed concrete supports infrastructure development in Indonesia, especially Kualanamu Railway overpass in Medan that use box girder with sectional height $2400 \mathrm{~mm}$ as a structural component. The case study of prestressed concrete box girder of Kualanamu Railway with 40 meters span is divided into 15 (fifteen) segments which will then be linked between its segments by the stressing process (giving prestressing style). This study explains the effectiveness of girder cross section which has internal tendons filled with $12.7 \mathrm{~mm}$ diameter strand steel cable totaling 60 pieces. Then,this study is analyzing the loss percentage of prestressing force that occurs in the tendon due to the shortening of the elastic, friction on the tendon, creep, shrinkage of the concrete and so on. By taking the data obtained from the field (PT Wijaya Karya Beton Tbk), load analysis by the method of SNI T-12 2004. Additionally introduced the steps on production process of box girder prestressed concrete, ranging from the reinforcements to casting in the precast concrete plant. Loss of prestressing force occurred at $12.94 \%$. Keywords : Prestressed Concrete, Box Girder, Loss of Prestressed
\end{abstract}

How to Cite: Ridwan, M, Irwan \&Panjaitan S. (2018). Analisa Struktur Box Girder Jalan Layang Kereta Api Kualanamu, JCEBT (Journal of Civil Engineering, Building and Transportation). 1 (2): 63-69. 


\section{PENDAHULUAN}

Sebagai bagian dari rencana pembangunan "Indonesia-sentris" yang tidak lagi terkonsentrasi di Pulau Jawa, pemerintahpun mulai gencar membangun infrastruktur perkeretaapian di Pulau Sumatera. Salah satunya pembangunan jalan layang kereta api sepanjang $\pm 8 \mathrm{~km}$ yang merupakan bagian dari rencana membangun jalur Stasiun Medan-Stasiun Bandara Kualanamu dengan total panjang $27 \mathrm{~km}$. Struktur girder memanjang dari jalan layang tersebut adalah jenis beton prategang box girder dengan bentang $40 \mathrm{~m}$ dan lebar 10,3 m, yang dalam konstruksinya girder-girder tersebut dicetak secara segmental di pabrik precast.

Tujuan pemberian gaya prategang adalah untuk menimbulkan tegangan awal dan lendutan awal (chamber) yang berlawanan dengan tegangan-tegangan yang ditimbulkan oleh beban-beban kerja. Dengan demikian konstruksi dapat memikul beban yang lebih besar lagi tanpa harus merubah mutu betonnya. Seluruh penampang beton menjadi efektif, akibat baja yang diberi gaya prategang dan diangkurkan ke beton. Sedangkan pada beton bertulang hanya sebagian dari penampang yang berada di atas garis netral yang bermanfaat.

Tujuan penelitian dari penulisan ini yaitu untuk mengetahui gaya-gaya yang bekerja akibat pelaksanaan jalan layang kereta api Kualanamu-Medan, Sumatera Utara. Selanjutnya melakukan analisa penampang yang dapat menahan lenturan akibat gaya-gaya yang bekerja di atasnya, sehingga diketahui besar persentase kehilangan gaya prategang (loss of prestress) pada bentang jalan layang tersebut.

Balok pratekan yang dianalisa pada studi kasus ini adalah segmen balok yang digunakan pada jalan layang kereta api Kualanamu-Medan, Sumatera Utara. Dari Track kereta api sepanjang $\pm 8 \mathrm{~km}$, bentang yang ditinjau hanya bagian Pier 39-Pier 40 sepanjang $40 \mathrm{~m}$.

Penganalisaan tidak termasuk desain abutment dan karakteristik pondasi yang digunakan, harga satuan dari bahan dan material yang digunakan, dan durasi pekerjaan dalam pelaksanaan konstruksinya dilapangan. Penganalisaan tulangan hanya untuk mengetahui persentase rasio tulangan sengkang segmen box girder tipe standar.

\section{METODE PENELITIAN}

Dengan mengambil data-data yang diperoleh dari lapangan (PT. Wijaya Karya Beton Tbk), a nalisa beban dengan metode SNI T-12 2004. Girder jalan layang Stasiun Medan-Stasiun Bandara Kualanamu berupa gelagar PC Box Girder dengan 
bentang $40 \mathrm{~m}$ dibagi dalam 15 (lima belas) segmen yang selanjutnya akan dihubungkan antar segmennya dengan proses stressing (pemberian gaya prategang).

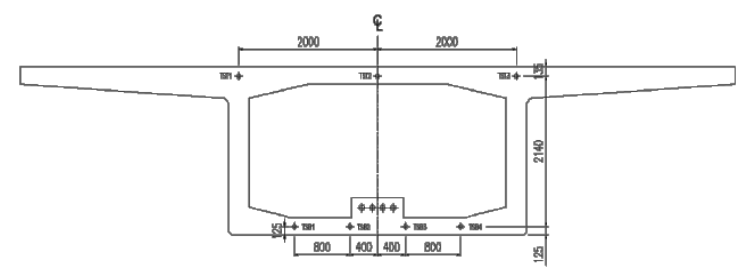

Gambar 1. Potongan melintang balok box girder

Gelagar jalan layang tersebut terbuat dari bahan beton dengan mutu $500 \mathrm{~kg} / \mathrm{cm}^{2}$ yang dikompositkan terhadap ballast dan bantalan jalan rel beton dengan 350 $\mathrm{kg} / \mathrm{cm}^{2}$.

Pada langkah perhitungan besar gaya dongkrak (jacking force) ada beberapa hal yang harus dipertimbangkan. Adapun halhal tersebut adalah :

\section{Desain Beton}

Menurut ACI, beton yang boleh mengalami prategang adalah beton yang telah berumur 28 hari dengan kuat tekan beton telah mencapai 30 sampai $40 \mathrm{MPa}$.

\section{Desain Baja}

Baja yang digunakan sebagai tulangan prategang merupakan jenis uncoated stress relieve seven wire strand low relaxation. Baja strand merupakan jenis yang paling banyak digunakan untuk penegangan post-tension. Strand yang digunakan pada proyek ini sesuai spesifikasi ASTM A416.

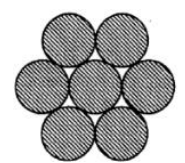

(a)

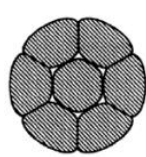

(b)
Gambar 2. Strand prategang 7 kawat (a) standard dan (b) yang dipadatkan

\section{Kehilangan Gaya Prategang}

Kehilangan gaya prategang dapat disebabkan oleh beberapa faktor antara lain (T.Y Lin, 1988):

a. Perpendekan elastis beton (ES)

b. Gesekan di sepanjang tendon $(W)$

c. Slip anchorage

d. Rangkak pada baja $(C R)$

e. Susut pada beton $(\mathrm{SH})$

f. Relaksasi pada baja

\section{Precast Segmental Box Girder}

Berbeda dengan sistem konstruksi monolit, sebuah jembatan segmental box girder terdiri dari elemen-elemen pracetak yang dipratekan bersama-sama oleh tendon eksternal (Prof. Dr.-Ing. G. Rombach, 2002).

\section{Elemen Struktural Jembatan Segmental Box Girder}

Jembatan segmental seharusnya dibangun seperti sturktur bentang tunggal untuk menghindari adanya sambungan kabel post-tension. Sehubungan dengan adanya eksternal post-tension maka 
diperlukan tiga macam segmen yang berbeda, diantaranya (Rombach, 2002):

a. Expansion Joint Segment: Bagian ini terletak tepat diatas abutment.

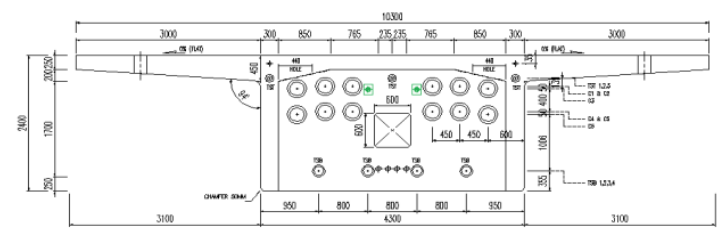

b. Deviator segment: Bagian ini dibutuhkan untuk pengaturan deviasi tendon.

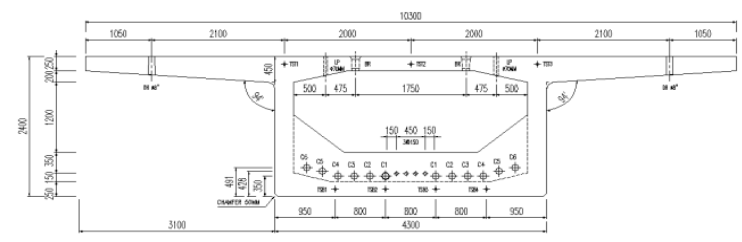

c. Standard segment: Dimensi standard box girder yang digunakan.

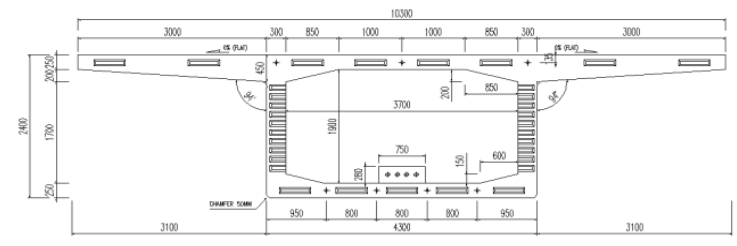

Gambar 3: Tipe Precast Box Girder Jalan Layang Kereta Api Kualanamu

\section{HASIL DAN PEMBAHASAN}

\section{Data Perencanaan}

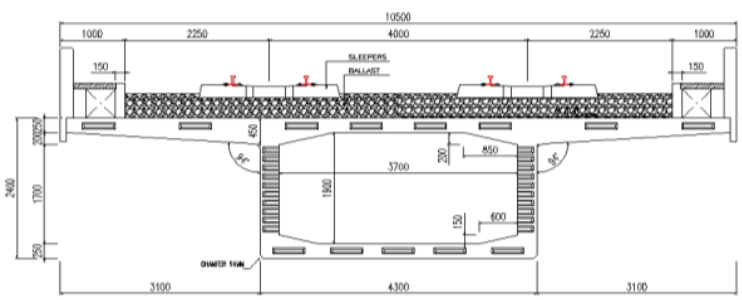

Gambar 4. Potongan Melintang Segmen Box Girder P39-P40
1. Fungsi jalan: Rel kereta double track

2. Tipe jembatan: Precast segmental box girder dengan menggunakan strukur beton pratekan tipe single box.

3. Panjang jembatan: $39.90 \mathrm{~m}$, Pier 39Pier 40 terdiri dari 1 bentang

4. Lebar jembatan: $10,5 \mathrm{~m}$

5. Lebar jalur lalu lintas (B): $8.5 \mathrm{~m}$

6. Jumlah Rel: 4 buah, 2 lajur 2 arah

7. Jumlah bantalan dalam 1 span: 134 bh

8. Tebal ballast: $42,3 \mathrm{~cm}$

\section{Data Bahan}

1. Kuat tekan beton prategang ( $\left.\mathrm{fc}^{\prime}\right): 40$ Мpa

2. Kuat tekan beton untuk struktur sekunder ( $\mathrm{fc}^{\prime}$ ): $28 \mathrm{Mpa}$

3. Mutu baja yang digunakan untuk penulangan box girder adalah baja mutu (fy): 400 Mpa.

4. Mutu baja yang digunakan untuk penulangan struktur sekunder adalah baja mutu (fy): $240 \mathrm{Mpa}$.

5. Jenis strands: Uncoated 7 wire super strand ASTM A-416 grade 270

6. Tegangan leleh strand $\left(\mathrm{f}_{\mathrm{py}}\right): 1580000$ $\mathrm{kPa}$

7. Diameter nominal strand (diameter): $0.0127 \mathrm{~m}$

8. Diameter selubung tendon: $65 \mathrm{~mm}$

9. Beban putus satu tendon ( $\left.\mathrm{P}_{\mathrm{b} 1}\right): 3746.4$ $\mathrm{kN}$

10. Diameter tulangan (diameter): $13 \mathrm{~mm}$ 


\section{Analisa Penampang}

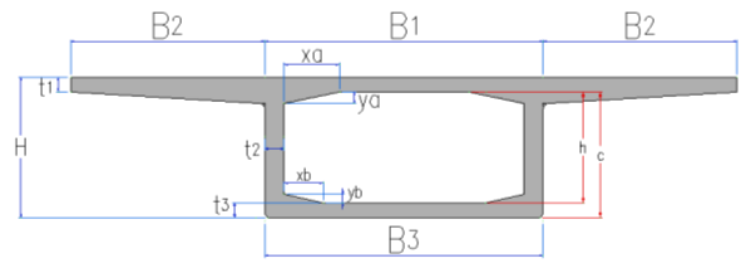

Gambar 5. Dimensi Penampang Box Girder

Tabel 1. Penempatan Tebal Pelat pada Penampang Segmen Box Girder

\begin{tabular}{|l|r|l|}
\hline Slab atas bag. Tengah. & $\mathrm{B}_{1}=$ & $4.30 \mathrm{~m}$ \\
& $\mathrm{t}_{1}=$ & $0.25 \mathrm{~m}$ \\
\hline Slab atas bag. Tepi. & $\mathrm{B}_{2}=$ & $3.00 \mathrm{~m}$ \\
& $\mathrm{t}_{1}=$ & $0.25 \mathrm{~m}$ \\
\hline Tinggi box girder. & $\mathrm{H}=$ & $2.40 \mathrm{~m}$ \\
\hline Dinding tengah. & $\mathrm{t}_{2}=$ & $0.30 \mathrm{~m}$ \\
\hline Slab bawah. & $\mathrm{B}_{1}=$ & $4.30 \mathrm{~m}$ \\
\hline & $\mathrm{t}_{3}=$ & $0.25 \mathrm{~m}$ \\
\hline
\end{tabular}

Tabel 2. Tebal Pelat sumbu koordinat pada Penampang Segmen Box Girder

\begin{tabular}{|l|c|c|}
\hline \multicolumn{3}{|c|}{ Penebalan pada pertemuan slab dan dinding } \\
\hline $\mathrm{x}_{\mathrm{a}}=$ & 0.85 & $\mathrm{~m}$ \\
\hline $\mathrm{y}_{\mathrm{a}}=$ & 0.20 & $\mathrm{~m}$ \\
\hline $\mathrm{x}_{\mathrm{b}}=$ & 0.60 & $\mathrm{~m}$ \\
\hline $\mathrm{y}_{\mathrm{b}}=$ & 0.15 & $\mathrm{~m}$ \\
\hline
\end{tabular}

Tabel 3. Lebar Total Box

\begin{tabular}{|l|l|l|}
\hline $\mathrm{B}_{\text {tot }}=\mathrm{B}_{1}+2 * \mathrm{~B}_{2}=$ & 10.30 & $\mathrm{~m}$ \\
\hline $\mathrm{h}=\mathrm{H}-\mathrm{t}_{1}-\mathrm{t}_{3}=$ & 1.90 & $\mathrm{~m}$ \\
\hline $\mathrm{c}=\mathrm{h}+\mathrm{t}_{3}=$ & 2.15 & $\mathrm{~m}$ \\
\hline
\end{tabular}

Tabel 4. Momen Inersia Penampang Segmen Box Girder

\begin{tabular}{|c|c|c|c|c|c|c|c|c|c|}
\hline \multirow[b]{2}{*}{ NO } & \multicolumn{2}{|c|}{ DIMENSI } & \multirow{2}{*}{$\begin{array}{l}\text { Shape } \\
\text { factor }\end{array}$} & \multirow{2}{*}{\begin{tabular}{|c|} 
Jumlah \\
Tampang
\end{tabular}} & \multirow{2}{*}{\begin{tabular}{|c} 
Luas \\
Tampang \\
$\mathrm{A}$ \\
$\mathrm{m}^{2}$ \\
\end{tabular}} & \multirow{2}{*}{\begin{tabular}{|c} 
Jarak thd \\
alas \\
$y$ \\
$m$
\end{tabular}} & \multirow{2}{*}{$\begin{array}{c}\text { Statis } \\
\text { Momen } \\
\mathrm{A}^{*} \mathrm{y} \\
\mathrm{m}^{3}\end{array}$} & \multirow{2}{*}{$\begin{array}{c}\text { Inersia } \\
\text { Momen } \\
\mathrm{A}^{*} \mathrm{y}^{2} \\
\mathrm{~m}^{4}\end{array}$} & \multirow{2}{*}{$\begin{array}{c}\text { Inersia } \\
\text { Momen } \\
\mathrm{I}_{0} \\
\mathrm{~m}^{4} \\
\end{array}$} \\
\hline & Lebar & Tebal & & & & & & & \\
\hline 1 & 4.3 & 0.25 & 1 & 1 & 1.075 & 2.28 & 2.446 & 5.56 & 0.0056 \\
\hline 2 & 3 & 0.25 & 1 & 2 & 1.5 & 2.28 & 3.413 & 7.76 & 0.00781 \\
\hline 3 & 3 & 0.2 & 0.5 & 2 & 0.6 & 2.08 & 1.25 & 2.6 & 0.00133 \\
\hline 4 & 0.85 & 0.2 & 0.5 & 2 & 0.17 & 2.08 & 0.354 & 0.74 & 0.00038 \\
\hline 5 & 0.3 & 1.9 & 1 & 2 & 1.14 & 1.2 & 1.368 & 1.64 & 0.34295 \\
\hline 6 & 0.6 & 0.15 & 0.5 & 2 & 0.09 & 0.3 & 0.027 & 0.01 & 0.00011 \\
\hline 7 & 4.3 & 0.25 & 1 & 1 & 1.075 & 0.13 & 0.134 & 0.02 & 0.0056 \\
\hline & & & & & 5.65 & & 8.992 & 18.34 & 0.36 \\
\hline
\end{tabular}

Gaya Prestress, Eksentrisitas, dan Jumlah Tendon

1. Kondisi Awal (Saat Transfer)

Gaya prategang awal, $\mathrm{P}_{\mathrm{t}}=8741.02 \mathrm{kN}$

Beban Putus Strand Total $P_{b s 1}=145.68 \mathrm{kN}$

Besar Ultimate Tensile Strenght (UTS) = $68.17 \%$

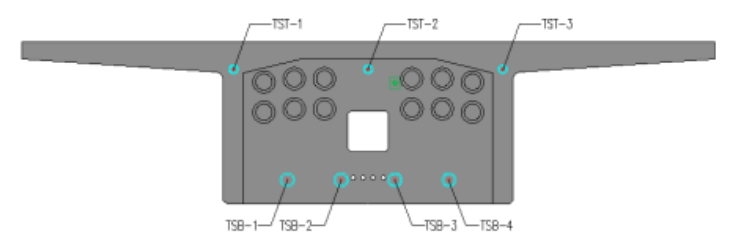

Gambar 5. Posisi tendon internal

Tabel 5. Jumlah tendon internal

\begin{tabular}{|c|c|c|c|}
\hline \multicolumn{4}{|c|}{ INTERNAL TENDON } \\
\hline \multicolumn{2}{|c|}{ PELAT ATAS: } & \multicolumn{2}{|c|}{ PELAT BAWAH : } \\
\hline $\begin{array}{c}\text { NO. } \\
\text { CABLE }\end{array}$ & $\begin{array}{l}\text { NO. PC STRAND } \\
\text { DIA, } 12,7 \mathrm{~mm}\end{array}$ & $\begin{array}{c}\text { NO. } \\
\text { CABLE }\end{array}$ & $\begin{array}{l}\text { NO. PC STRAND } \\
\text { DIA. } 12,7 \mathrm{~mm}\end{array}$ \\
\hline TST-1 & 4 & TSB-1 & 12 \\
\hline TST -2 & 4 & TSB-2 & 12 \\
\hline TST -3 & 4 & TSB-3 & 12 \\
\hline \multirow{2}{*}{ total } & \multirow{2}{*}{12} & TSB-4 & 12 \\
\hline & & total & 48 \\
\hline
\end{tabular}

2. Kondisi Akhir (Saat Service)

Gaya prestress akhir setelah kehilangan tegangan (loss of presstress) sebesar $30 \%$ :

$\mathrm{P}_{\text {eff }}=5948.35 \mathrm{kN}$

Besar Ultimate Tensile Strength (UTS) = $123.77 \%$

\section{Posisi Tendon}

Tabel 6. Eksentrisitas masing-masing tendon

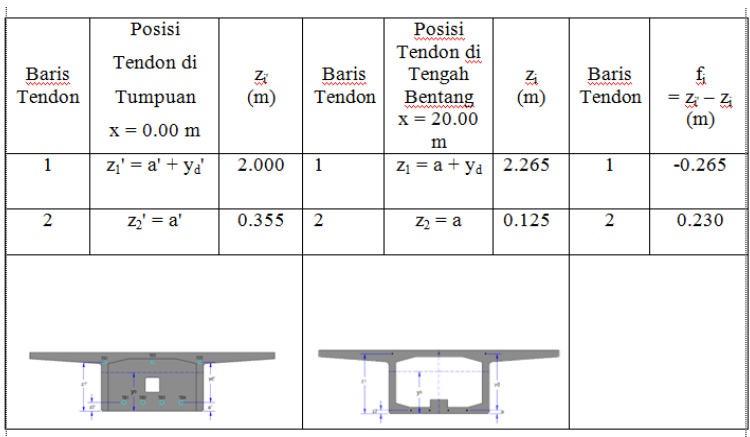


4. Sudut Angkur

Tabel 7. Sudut angkur tendon internal

\begin{tabular}{|c|c|c|c|c|c|c|c|}
\hline $\begin{array}{c}\text { NO } \\
\text { TENDON }\end{array}$ & $\begin{array}{c}\text { Jumlah } \\
\text { Strand Dia. } \\
12,7 \mathrm{~mm}\end{array}$ & $\begin{array}{c}\text { DIAMETER } \\
\text { SELUBUNG } \\
(\mathrm{mm})\end{array}$ & Eksentrisitas & $\mathrm{f}_{\mathrm{i}}(\mathrm{m})$ & $\mathrm{d}_{\mathrm{Y}} / \mathrm{d}_{\mathrm{X}}$ & \multicolumn{2}{|c|}{ SUDUT ANGKUR } \\
\hline 1 & 12 & 65 & $\mathrm{f}_{1}$ & -0.265 & -0.02657 & $\mathrm{a}_{1}=-0.03$ & $\mathrm{rad}=-1.5^{\circ}$ \\
\hline 2 & 48 & 65 & $\mathrm{f}_{2}$ & 0.23 & 0.02306 & $\mathrm{a}_{2}=0.02$ & $\mathrm{rad}=1.3^{\circ}$ \\
\hline
\end{tabular}

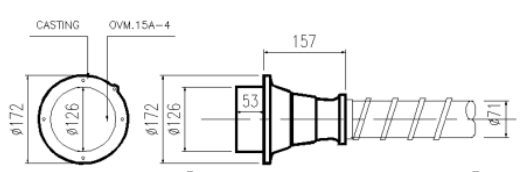

Gambar 6. Detail casting internal tendon

5. Kehilangan tegangan (Loss of prestress)

Tabel 8. Loss of Presstress

\begin{tabular}{|c|c|c|c|}
\hline Gaya & $(\mathrm{kN})$ & $\%$ UTS & Loss of prestress \\
\hline$P_{j}$ & 8497.6 & $54.51 \%$ & Anchorage friction \\
\hline$P_{i}$ & 8015.44 & $71.32 \%$ & Relaxation of tendon \\
\hline $\mathrm{P}_{\text {eff }}$ & 7397.73 & $123.77 \%$ & \\
\hline
\end{tabular}

Kehilangan gaya presstress total yang diperoleh sebesar $12.94 \%<30 \%$ cukup dekat dengan estimasi awal (kehilangan gaya presstress akhir).

6. Tata Letak Dan Trace Kabel

Tabel 9. Koordinat internal tendon

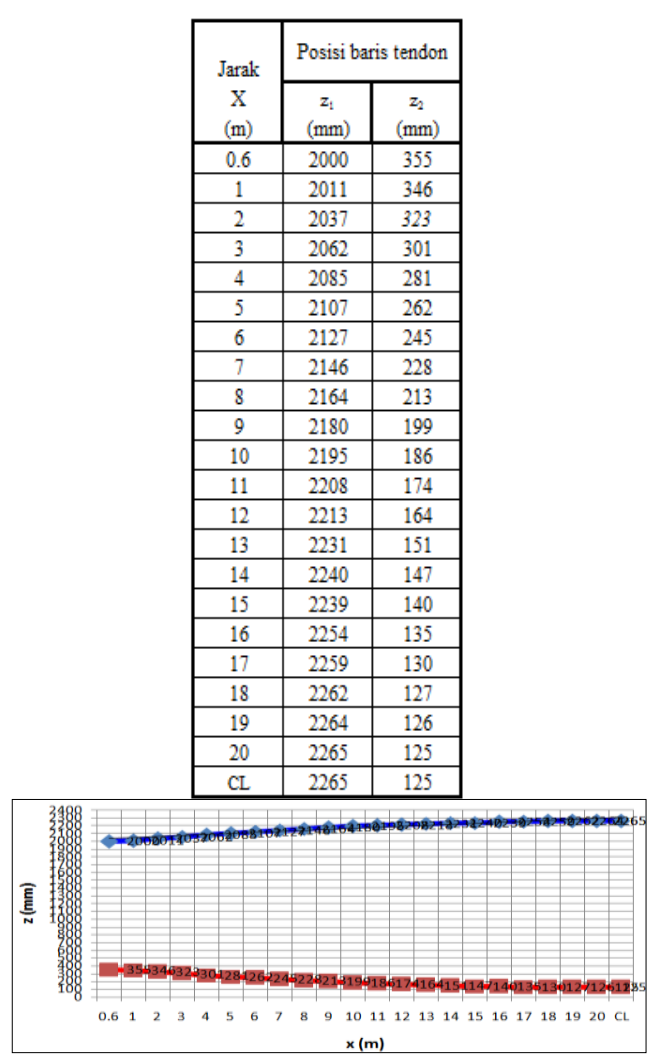

Gambar 7. Trace masing - masing tendon

\section{Penulangan Box Girder}

1. Perencanaan jumlah bursting steel internal tendon

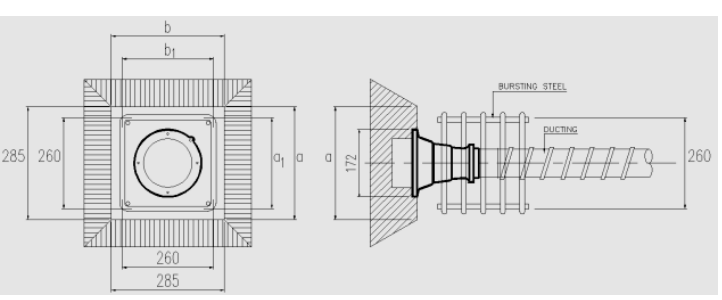

Gambar 8. Detail bursting steel internal tendon tst

2. Penulangan Pada Segmen Box Girder

a) Plat Dinding Tepi

Tebal plat dinding $\left(t_{2}\right)=300 \mathrm{~mm}$

Diameter tulangan (D) $=19 \mathrm{~mm}$

Jarak tulangan yang diperlukan $(\mathrm{s})=100$ $\mathrm{mm}$

b) Plat Bawah

Tebal plat dinding $\left(\mathrm{t}_{3}\right)=250 \mathrm{~mm}$

Diameter tulangan (D) $=13 \mathrm{~mm}$

Jarak tulangan yang diperlukan (s) $=200$ $\mathrm{mm}$

c) Plat Atas

Tebal plat dinding $\left(\mathrm{t}_{1}\right)=250 \mathrm{~mm}$

Diameter tulangan (D) $=22 \mathrm{~mm}$

Jarak tulangan yang diperlukan (s) $=200$ $\mathrm{mm}$

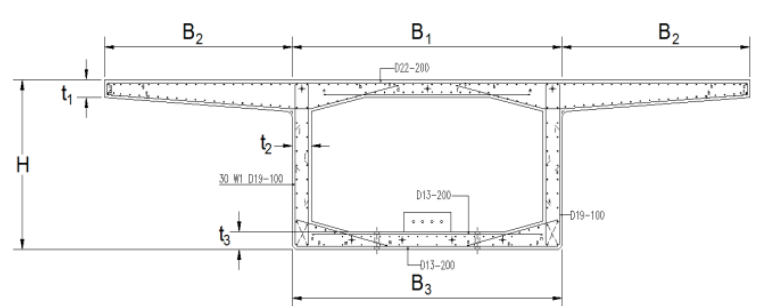

Gambar 9. Penulangan Segmen Box Girder 


\section{SIMPULAN}

Analisis mengenai perilaku dilakukan dengan mempertimbangkan ketidakelastisan material dan beban batas (ultimate) yang bekerja. Apabila gaya prategang bekerja tidak pada pusat penampang, tetapi eksentrisitas, maka ada tambahan tegangan akibat eksentrisitas tersebut. Di dalam suatu sistem struktur beton prategang selalu terdapat kehilangan gaya prategang baik akibat sistem penegangan maupun akibat waktu. Kehilangan gaya prestress yang terjadi sebesar $12,94 \%$. Letak dan bentuk bursting steel tendon internal harus menyesuaikan besarnya gaya tarik yang terjadi pada zona pengangkuran dengan menggunakan diameter besi D13 jarak 50 $\mathrm{mm}$.

\section{DAFTAR PUSTAKA}

Budiadi, A. (2008). Desain Praktis Beton Prategang. Andi, Yogyakarta.

Ilham, N.M. (2008). "Perhitungan Box Girder Beton Prestress Gejayan Fly Over Yogyakarta".

Lin, T.Y., dan Ned H.B. (1988). Desain Struktur Beton Prategang. Edisi ke 3. Jilid 1. Diterjemahkan oleh: Daniel Indrawan M.C.E. Erlangga, Jakarta.

Nawy, E.G. (2001). Beton Prategang Suatu Pendekatan Mendasar. Edisi ke 3. Jilid 1. Diterjemahkan oleh: Bambang Suryoatmo. Erlangga, Jakarta.

Rombach, G. (2002). "Precast segmental box girder bridges with external prestressing: Design and Construction".

Wijaya Karya Beton, PT. 2015. "Dokumentasi Produksi dan Shop Drawing Box Precast Pembanguanan Jalan KA Layang Antara Medan-Araskabu-Kualanamu". Binjai 